\title{
Effects of TRH and an Analog, DN-1417 on the Activities of Single Neurons in the Nucleus Accumbens, Cerebral Cortex and Caudate-putamen of Rats
}

\author{
TADATOSHI HASHIMOTO, NAOHISA FUKUDA, YOSHIAKI SAJI \\ AND YUJI NAGAWA \\ Central Research Division, Takeda Chemical Industries Ltd., Osaka, 532 Japan
}

Received for publication October 6, 1983

\begin{abstract}
Summary: The actions of TRH and its analog, $\gamma$-butyrolactone- $\gamma$-carbonylhistidyl prolinamide citrate (DN-1417) on the unit activities of the cerebral cortex, caudate-putamen and nucleus accumbens were examined using a microelectrophoretic technique in anesthetized rats. Over $80 \%$ of the neurons examined in the nucleus accumbens responded to TRH and DN-1417. The effects were mainly inhibitory, but excitatory effects $(12-17 \%)$ were also detected. In the cerebral cortex and caudate-putamen, only one-third of the neurons were depressed by TRH and DN-1417. DN-1417 exerted an effect similar to TRH on almost all neurons. Dopamine affected almost all neurons. Its main effect was inhibition, but excitation was also observed in some neurons of the nucleus accumbens. Methamphetamine mimicked dopamine in the three regions. However, it was observed that TRH and DN-1417 mimicked dopamine only in the nucleus accumbens neurons. Furthermore, both the inhibitory and excitatory actions of TRH, DN-1417 or dopamine were attenuated by the dopamine receptor antagonist, haloperidol, which was administered systemically. These results suggest that: (1) TRH and DN-1417 have similar actions on the neurons; (2) TRH and DN-1417 act more selectively than dopamine and methamphetamine on the nucleus accumbens neurons, and they may act indirectly on dopaminergic neurons of the nucleus accumbens through an action on presynaptic sites; (3) Endogenous TRH may play a physiological role as a neuromodulator of dopaminergic transmission in the nucleus accumbens.
\end{abstract}

Key words: TRH - DN-1417 - dopamine - unit recording - microelectrophoresis - nucleus accumbens - rat

\section{Introduction}

Thyrotropin-releasing hormone (TRH), a hypothalamic substance which regulates pituitary-thyroid function, is widely distributed in the brain (Hökfelt et al. 1975; Winokur and Utiger, 1975). It has been shown that TRH produces many central nervous effects, such as antagonism to central depressants (Breese et al. 1975), potentiation of the actions of L-DOPA
(Plotnikoff et al. 1972) and a motor stimulatory action (Goujet et al. 1975). Also, nerve terminals containing TRH (Hökfelt et al. 1975), high affinity TRH-binding sites (Burt and Snyder, 1975) and TRH degradation enzymes (Griffiths et al. 1976) have been found within the brain. It has been proposed that TRH may act as a neurotransmitter or neuromodulator within the central nervous system (Emson, 1979; Morley, 1979; Snyder, 1980). 
Miyamoto and Nagawa (1977) reported that the nucleus accumbens is an important site for the locomotor stimulatory action of TRH because bilateral injection of TRH into the nucleus accumbens, regarded as the terminal part of the mesolimbic dopaminergic system, exerted a more prominent stimulatory action than injection into other brain regions. Also, the TRH effect was markedly attenuated by pretreatment with haloperidol, a dopamine receptor antagonist. There is also neurochemical evidence that TRH increases $\left[{ }^{3} \mathrm{H}\right]$-dopamine release from superfused slice preparations of the rat nucleus accumbens and striatum (Kerwin and Pycock, 1979; Narumi et al. 1979).

The nucleus accumbens, mesolimbic dopaminergic system terminus, receives efferent inputs from the ventral tegmentum A10 (Anden et al. 1966) and limbic structures, including the amygdala, hippocampus and cingulate gyrus, related to emotional activity. It projects to the globus pallidus and substantia nigra thereby controlling the motor performance (Conrad and Pfaff, 1976; DeFrance and Yoshihara, 1975; Dray and Oakley, 1977; Ito et al. 1974; Nauta et al. 1978; Takaori et al. 1981). The inputs from the amygdala and A10 converge on the nucleus accumbens (Mogenson et al. 1980; Yim and Mogenson, 1982). Mogenson et al. (1980) proposed that the nucleus accumbens acts as a functional interface between emotional inputs from the limbic system and motor outputs to the nigrostriatal dopaminergic system.

In the present investigation, the effect of TRH on the single neuron activities of the nucleus accumbens, cerebral cortex and caudate-putamen were examined with microelectrophoretic methods. The effect of a TRH analog, DN-1417, $\gamma$-butyrolactone - $\gamma$ - carbonyl - histidyl - prolinamide citrate, which has less endocrine activity and more central nervous activity, was also observed (Fukuda et al. 1979; Miyamoto et al. 1981; Shikata et al. 1982).

\section{Materials and Methods}

\section{Animals used}

Male Sprague-Dawley rats weighing $230-275 \mathrm{~g}$ were anesthetized with urethane $(0.8 \mathrm{~g} / \mathrm{kg}$, ip) and $\alpha$-chloralose $(80 \mathrm{mg} / \mathrm{kg}$, ip).

\section{Unit recording}

Anesthetized rats were mounted in a Kopf stereotaxic frame with an incisor bar $2.4 \mathrm{~mm}$ below the ear bars. The right cerebral hemisphere was exposed and covered with $2 \%$ agar dissolved in Tyrode's solution. The recording electrode was lowered through a burr hole in the skull to the appropriate site according to coordinates of König and Klippel (1963). The coordinates used for cerebral cortex, caudate-putamen and nucleus accumbens were $9400 \mu \mathrm{m}-9800 \mu \mathrm{m}$ anterior, $900 \mu \mathrm{m}-1400 \mu \mathrm{m}$ lateral to sagittal sinus at various depths.

The extracellular unit recording technique was similar to that described by Oomura (1976). Briefly, micropipettes filled with $0.5 \mathrm{M}$ sodium acetate saturated with Pontamine sky blue with tip diameters of less than $1 \mu \mathrm{m}$ were used (tip impedance: $10-15 \mathrm{M} \Omega$ ). A single recording electrode was attached with polystyrene $Q$ DOPE (G. C. Electronics) to a seven barrelled glass micropipettes for drug application.

Substances were applied by passing a constant current of appropriate polarity and strength through the pipette. Since almost all the neurons had a very low spontaneous firing rate, the firing rate was maintained at about 10 spikes/sec by continuous glutamate (1-10 nA) application, so the drug effects could be observed. Only neurons which were excited by glutamate were used in these experiments. The potentials were amplified, and the output from the preamplifier was recorded on an oscilloscope (VC-9, Nihon Kohden) for initial observation, and entered into a window discriminator and rate meter (time 
constant: $1 \mathrm{sec})$. Data was stored on a magnetic tape recorder ( $\mathrm{R} 280 \mathrm{LT}$, TEAC).

\section{Drugs used}

Each barrel was filled with one of the following substances for microelectrophoretic application: $0.5 \mathrm{M}$ TRH-T (L-pyroglutamyl-L-histidyl-L-prolinamide L-tartrate monohydrate, Takeda) dissolved in $0.5 \mathrm{~N} \mathrm{NaOH}$ at $\mathrm{pH} 5.5-6.0 ; 0.5 \mathrm{M} \mathrm{DN}-1417$ ( $\gamma$-butyrolactone - $\gamma$-carbonyl - L-histidyl-Lprolinamide citrate, Takeda) dissolved in $0.5 \mathrm{~N} \mathrm{NaOH}$ at pH $5.0-5.5 ; 0.5 \mathrm{M}$ dopamine $\mathrm{HCl}$ (DA, Sigma) at pH $5.0-5.5 ; 0.5 \mathrm{M}$ methamphetamine $\mathrm{HCl}$ (MAP, Dainippon) at $\mathrm{pH} 5.5 ; 0.5 \mathrm{M}$ acetylcholine chloride (ACh, Wako Pure Chemicals) at pH 5.0; $50 \mathrm{mM} \gamma$-aminobutyric acid (GABA, Wako Pure Chemicals) dissolved in $0.5 \mathrm{M} \mathrm{NaCl}$ at pH 6.0-6.5;0.5M L-glutamate (Wako Pure Chemicals) at $\mathrm{pH} 7.5$; and $0.5 \mathrm{M} \mathrm{NaCl}$ at $\mathrm{pH}$ 6.0-6.5. Haloperidol (Serenace ${ }^{\circledR}$, Dainippon) diluted with $0.9 \% \mathrm{NaCl}$ was injected ip to some animals.

\section{Criteria for drug effects}

An increase or decrease in firing rate at $30 \%$ or more after drug application was considered to be an excitation or inhibition, respectively.

\section{Histological identification of electrode location}

At the termination of the experiment, the recording site was marked for histological identification by injecting Pontamine sky blue as an anion with a continuous DC current for 10 to $20 \mathrm{~min}$.

\section{Results}

Effects of TRH and DN-1417 on the cerebral cortex, caudate-putamen and nucleus accumbens neurons

As shown in Table 1, 46 of 125 and 46 of 143 cerebral cortical neurons were suppressed by TRH and DN-1417, respectively. The majority (62 and $66 \%$ ) of the cortical neurons were unaffected by TRH and DN1417. An excitatory response was induced by TRH and DN-1417 in less than $2 \%$ of the neurons. About one-third of the caudate-putamen neurons were suppressed, two-thirds were unaffected, and less than $3 \%$ of the neurons were excited by TRH or DN-1417 application.

85 and $89 \%$ of the nucleus accumbens neurons were affected by TRH and DN1417, respectively. Inhibitory effects were observed in about $73 \%$ of the neurons and excitatory responses were observed in 12 and $17 \%$ of the neurons during TRH and DN-1417 application, respectively. The proportion of excitatory responses induced by TRH and DN-1417 was greater than in cortical and caudate-putamen neurons.

The effects of TRH and DN-1417 were dose-dependent and reproducible, irrespective of the number of applications. The latency of onset of the drug effect was 2 to $20 \mathrm{sec}$. TRH and DN-1417 almost always produced the same response in individual neurons.

Effects of DA, MAP, GABA and ACh on activities in neurons of the cerebral cortex, caudate-putamen and nucleus accumbens

$D A$ : Almost all neurons in the cerebral cortex, caudate-putamen and nucleus accumbens were affected by DA application (78, $94 \%$ and $96 \%$, respectively). Its primary effect was suppressive (Table 1).

In the nucleus accumbens, the excitatory effect of DA was observed more frequently $(9.9 \%)$ than in the other two regions. DA produced a dose-dependent effect with an onset latency of 2 to $5 \mathrm{sec}$ (Fig. 1).

The effects of TRH, DN-1417 and MAP on DA-responsive neurons were studied (Fig. 2). It was noted that TRH and DN1417 had similar actions on the DA response in most of the nucleus accumbens neurons, which responded to DA by either inhibition or excitation. TRH and DN-1417 had smaller inhibitory effects in cortical 
TABLE 1

Number of neurons affected by TRH, DN-1417, dopamine, methamphetamine $(M A P)$, acetylcholine $(A C h)$ and $G A B A$

\begin{tabular}{lcrrrrrr}
\hline & $\begin{array}{c}\text { Number of } \\
\text { neurons tested }\end{array}$ & Excited $(\%)$ & Inhibited $(\%)$ & Unaffected $(\%)$ \\
\hline Cortical neuron & & & & & & & \\
TRH & 125 & & & & & & \\
DN-1417 & 143 & 3 & $(2.1)$ & 46 & $(36.8)$ & 78 & $(62.4)$ \\
DA & 171 & 2 & $(1.2)$ & 131 & $(76.6)$ & 94 & $(65.7)$ \\
MAP & 45 & 1 & $(2.2)$ & 33 & $(73.3)$ & 11 & $(24.5)$ \\
ACh & 147 & 109 & $(74.1)$ & 27 & $(18.4)$ & 11 & $(7.5)$ \\
GABA & 65 & 0 & $(0.0)$ & 65 & $(100.0)$ & 0 & $(0.0)$ \\
\hline Caudate-putamen neuron & & & & & & & \\
TRH & 97 & 3 & $(3.1)$ & 32 & $(33.0)$ & 62 & $(63.9)$ \\
DN-1417 & 105 & 3 & $(2.9)$ & 27 & $(25.7)$ & 75 & $(71.4)$ \\
DA & 132 & 3 & $(2.3)$ & 121 & $(91.6)$ & 8 & $(6.1)$ \\
MAP & 42 & 0 & $(0.0)$ & 34 & $(81.0)$ & 8 & $(19.0)$ \\
ACh & 98 & 88 & $(89.8)$ & 6 & $(6.1)$ & 4 & $(4.1)$ \\
GABA & 23 & 0 & $(0.0)$ & 23 & $(100.0)$ & 0 & $(0.0)$ \\
\hline Nucleus Accumbens neuron & & & & & & & \\
TRH & 246 & 30 & $(12.2)$ & 179 & $(72.8)$ & 37 & $(15.0)$ \\
DN-1417 & 239 & 40 & $(16.7)$ & 172 & $(72.0)$ & 27 & $(11.3)$ \\
DA & 274 & 27 & $(9.9)$ & 236 & $(86.1)$ & 11 & $(4.0)$ \\
MAP & 40 & 6 & $(15.0)$ & 29 & $(72.5)$ & 5 & $(12.5)$ \\
ACh & 75 & 54 & $(72.0)$ & 14 & $(18.7)$ & 7 & $(9.3)$ \\
GABA & 49 & 0 & $(0.0)$ & 49 & $(100.0)$ & 0 & $(0.0)$ \\
\hline
\end{tabular}

\section{N. ACCUMBENS}
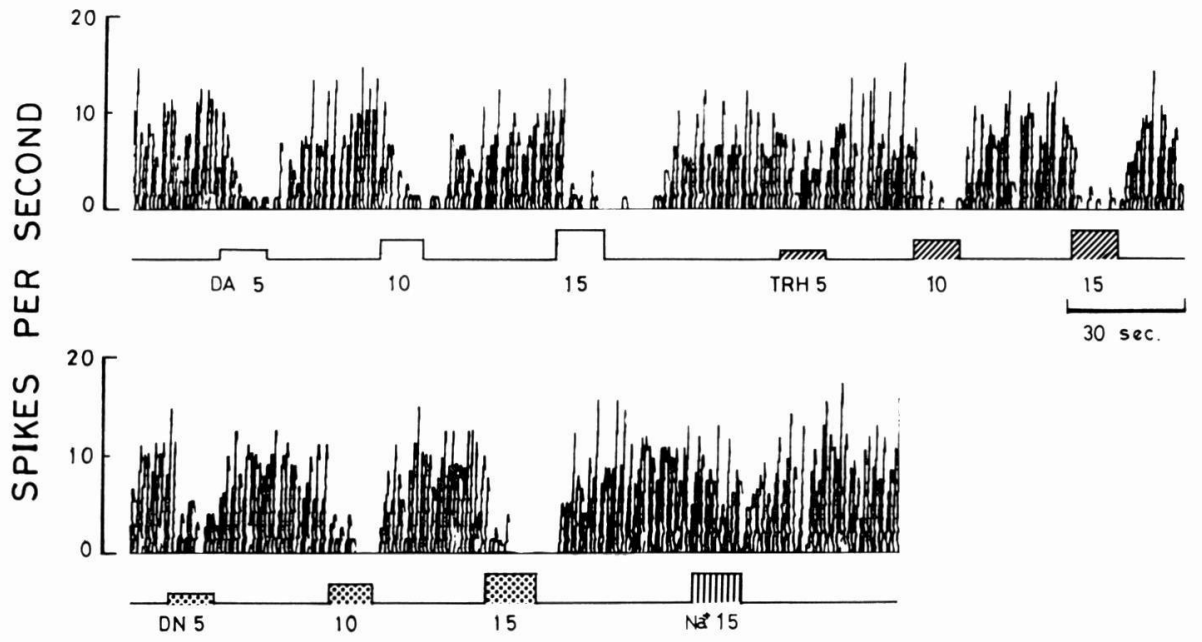

Fig. 1. Dose-dependent effects of electrophoretically applied dopamine (DA), TRH and DN-1417 (DN) on the firing rate of a neuron in the nucleus accumbens. The neuron was driven by the continuous electrophoretic application of glutamic acid $(5 \mathrm{nA})$. The actions of TRH and DN were similar to the actions of DA. 

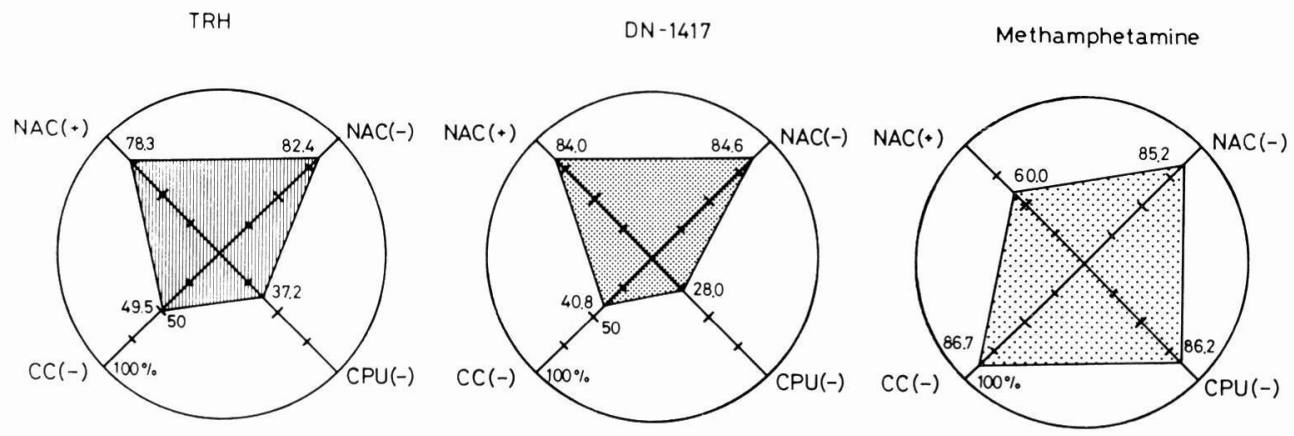

Fig. 2. Effects of TRH, DN-1417 and Methamphetamine on the neurons which were inhibited or excited by dopamine in the neurons of nucleus accumbens (NAC), cerebral cortex (CC) and caudate-putamen (CPU). Figures in the circle indicate the percent of neurons which were inhibited or excited by TRH, DN-1417 and methamphetamine. Number of neurons tested was 10 to 204 . ( $(-)$ : neurons inhibited by dopamine, $(+)$ : neurons excited by dopamine.

and caudate-putamen neurons which responded to DA than in the nucleus accumbens. MAP produced an effect similar to DA in all three brain regions.

$M A P$ : The effect of MAP on neurons in the cortex, caudate-putamen and nucleus accumbens was predominantly suppressive $(73,81 \%$ and $73 \%$, respectively). Only one of the 45 cells in the cortex and none of 42 cells in the caudate-putamen, gave an excitatory response to MAP.

In the nucleus accumbens, MAP induced an excitatory response more frequently $(15 \%)$ than in the other two regions (Table 1). The latency of onset for the drug effect was 2 to $5 \mathrm{sec}$.

$G A B A$ : All neurons were suppressed by GABA and the effect was dose-dependent. The latency of onset for GABA was shorter than for the other drugs. A postinhibitory excitation, after teh GABA application, was frequently observed.

ACh: As shown in Table 1, ACh induced excitatory effects on more than $70 \%$ of the neurons in the cerebral cortex, caudate-putamen and nucleus accumbens. In- hibitory effects were also seen in the cerebral cortex (18.4\%), caudate-putamen $(6.1 \%)$ and nucleus accumbens $(18.7 \%)$. The effects of $\mathrm{ACh}$ were dose-dependent, and the onset latency for $\mathrm{ACh}$ was 2 to 5 sec. A rebound inhibition after a pronounced excitation was observed in some neurons.

Effect of haloperidol on the effects of TRH, $D N-1417$ and DA in the nucleus accumbens

Haloperidol, ip, slightly increased the spontaneous firing rate of the nucleus accumbens neurons in which DA had an inhibitory action (Fig. 3), and it decreased the spontaneous rate if DA had an excitatory effect. The effect of haloperidol pretreatment was studied on the neurons which responded to DA, TRH and DN1417 with either inhibition or excitation. The inhibitory action of DA, TRH and DN-1417 were markedly attenuated by pretreatment with haloperidol. The excitatory effects of DA, TRH and DN-1417 were also attenuated by haloperidol (Fig. 3). 


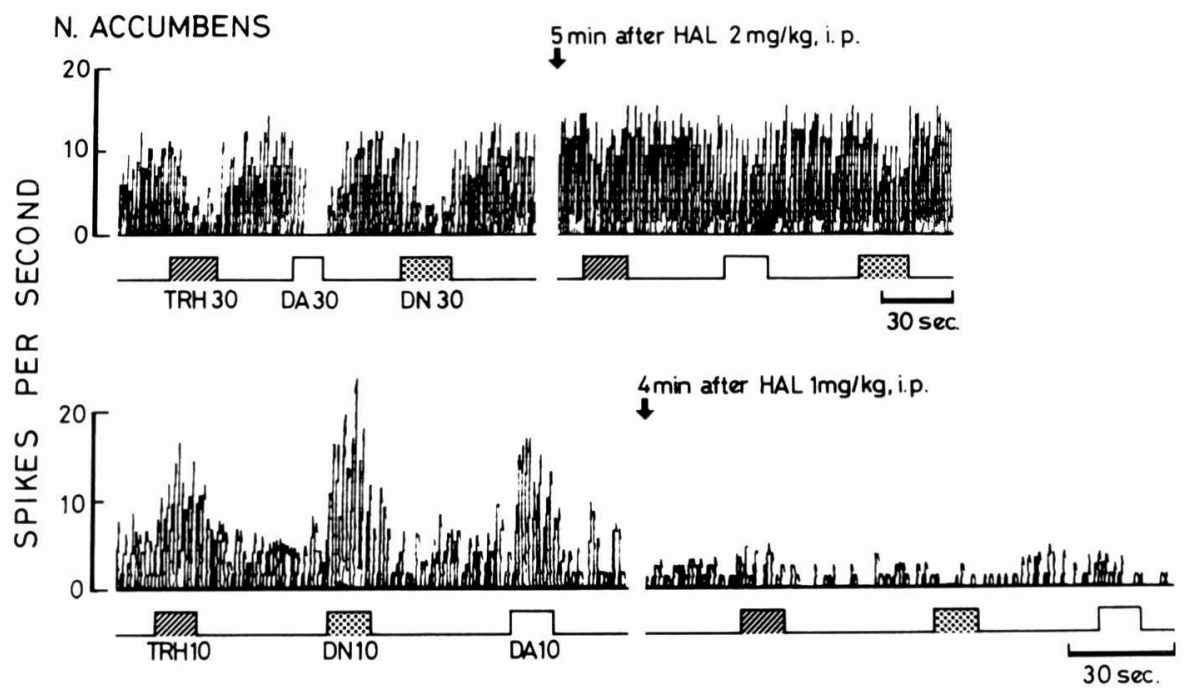

Fig. 3. Effect of haloperidol (HAL; 2 and $1 \mathrm{mg} / \mathrm{kg}$, ip) on the inhibitory and excitatory actions of electrophoretically applied TRH, dopamine (DA) and DN-1417 (DN). The neuron was driven by the continuous application of glutamic acid $(15 \mathrm{nA})$. After the $\mathrm{HAL}$ injection, the inhibitory and excitatory actions of TRH, DA and DN were almost completely blocked.

\section{Discussion}

Microelectrophoretic applications of TRH and DN-1417 affected a large proportion $(85-89 \%)$ of neurons in the nucleus accumbens, but only a small proportion (less than $40 \%$ ) of neurons in the cerebral cortex and caudate-putamen. DA affected almost all neurons in these regions (78-96 $\%)$. There are several reports on the effects of TRH on cortical neurons which describe suppressive effects (Morley, 1979; Renaud and Martin, 1975), no obvious effects (Winokur and Beckman, 1978; Yarbrough, 1976) and either excitatory or inhibitory effects (Braitman et al. 1980).

TRH and DN-1417 suppressed the firing in 37 and $32 \%$ of the cortical neurons, respectively. Bunny et al. (1976) reported that DA and norepinephrine elicited an inhibitory action on neurons in layers $I$, III, V and VI of the frontal cortex. Stone et al. (1975) found that DA and amphe- tamine had an inhibitory action on almost all cortical neurons. TRH and DN-1417 have been reported to have a stimulatory effect on $\left[{ }^{14} \mathrm{C}\right]$-norepinephrine release from cortical slices although they are less active than MAP (Narumi et al. 1979). The results of the present study suggest that the effect of TRH or DN-1417 on cerebral cortical neurons is mediated via a catecholaminergic system in the brain.

Yarbrough (1976) and Braitman (1980) reported that TRH potentiated the excitatory action of $\mathrm{ACh}$ on cortical neurons. In other reports, no potentiating effect of TRH on ACh-responsive cortical neurons was found (Renaud and Martin, 1975). In the present study, TRH or DN-1417 affected some ACh-sensitive and ACh-insensitive neurons in the cerebral cortex. This was also observed in the caudate-putamen and the nucleus accumbens neurons. Moreover, GABA did not act like TRH, DN-1417 and DA in regard to latency, 
duration and direction of the GABA effect. This was also found in the caudate-putamen and the nucleus accumbens neurons.

In caudate-putamen which is the terminus of the nigrostriatal DA system, TRH and DN-1417 affected 36 and 28.6\% of the neurons mainly in an inhibitory manner. On the other hand, DA and MAP inhibited most all the neurons (92 and 81 \%). TRH and DN-1417 had the same effect on caudate-putamen neurons as DA in 37 and $28 \%$ of the neurons tested, respectively. MAP produced the same effect as DA in $86 \%$ of the caudate-putamen neurons. There are contrasting reports (Connor, 1970; Kitai et al. 1976; McLennan and York, 1967; Spencer and Havlicek, 1975) whether DA can produce an excitatory or inhibitory action on the caudateputamen neurons, but the reason for this discrepancy is unclear (Woodruff et al. 1976).

It has been proposed that the nucleus accumbens is a functional interface between the limbic and motor systems, and that DA has a role in modulating the nucleus accumbens (Mogenson et al. 1980; Yim and Mogenson, 1982). TRH or DN1417 applied microelectrophoretically affected most neurons in the nucleus accumbens (85\% and $89 \%$, respectively), mainly in an inhibitory manner. However, excitatory effects were also detected with TRH and DN-1417 application in 12 and $17 \%$ of the neurons, respectively. DA also had excitatory and inhibitory effects on the nucleus accumbens neurons in the present investigation.

Both the excitatory and inhibitory effects of DA were reduced by pretreatment with haloperidol, a DA receptor antagonist. Almost all cells responding to DA also re sponded to TRH, DN-1417 or MAP in a similar-manner. Furthermore, both the excitatory and inhibitory effects of TRH and DN-1417 in the nucleus accumbens neurons were attenuated or blocked by haloperidol treatment. These results sug- gest that the action of TRH or DN-1417 on the nucleus accumbens neurons is mediated via either a direct activation on DA receptors or an indirect activation of an endogenous dopaminergic system within the nucleus accumbens.

Miyamoto and Nagawa (1977) reported that the mesolimbic dopaminergic system was involved in the motor stimulatory action of TRH. An ip injection of TRH, or a bilateral microinjection of TRH into the nucleus accumbens, induced a motor stimulatory action in rats. This action was attenuated by pretreatment with ip or bilateral injection of haloperidol into the nucleus accumbens, and by systemic administration of pimozide (a DA receptor antagonist), or $\alpha$-methyl-p-tyrosine (a tyrosine hydroxylase inhibitor), and was augmented by pargyline (a monoamine oxidase inhibitor). Also, there is evidence that TRH increases $\left[{ }^{3} \mathrm{H}\right]-\mathrm{DA}$ release from the rat nucleus accumbens slices in vitro (Kerwin and Pycock, 1979; Miyamoto et al. 1979). These findings indicate that the effects of TRH and DN-1417 on the nucleus accumbens neurons are mediated via the dopaminergic system in the nucleus accumbens. A large dose of TRH (100 mg $/ \mathrm{kg}$, ip) is required to produce a rotating behavior directed to the lesioned side in rats with a unilateral nigrostriatal lesion from the administration of 6-hydroxydopamine (Fukuda et al. 1979). In neurochemical studies, higher concentrations of TRH are necessary to release $\left[{ }^{3} \mathrm{H}\right]-\mathrm{DA}$ from striatal slices than from nucleus accumbens slices in vitro (Narumi et al. 1983). In contrast to the effect of TRH, no differences were found in the concentrations of MAP necessary to release $\left[{ }^{3} \mathrm{H}\right]-\mathrm{DA}$ in nucleus accumbens and striatal slice preparations (Miyamoto et al. 1979; Narumi et al. 1979). These findings agree with the present data that TRH and DN-1417 act more selectively on the nucleus accumbens neurons than on the cortical and caudateputamen neurons. 
In summary, more cells which were sensitive to TRH and DN-1417 were found in the nucleus accumbens than in the cortical and caudate-putamen. Also, the effect of TRH and DN-1417 on the nucleus accumbens neurons is probably mediated via a dopaminergic system, which releases DA within the nucleus accumbens. Moreover, the present study supports the hypothesis that the nucleus accumbens has a role in eliciting the locomotor stimulatory action of TRH and DN-1417. Since it has been proposed that the nucleus accumbens is a functional interface between the limbic and motor systems, further experiments should be undertaken to clarify the physiological role of TRH in the nucleus accumbens.

Acknowledgments: The authors sincerely thank Professor Y. Oomura for valuable instruction in unit recording and electrophoretic techniques, and Dr. N.Shimizu for preparation of the unit recording devices. We also thank Dr. $\mathrm{K}$. Takahama for instruction in basic techniques for electrophysiological experiments.

\section{References}

Anden, N. -E., Dahlström, A., Fuxe, K., Larsson, K., Olson, L. and Ungerstedt, U. (1966). Ascending monoamine neurons to the telencephalon and diencephalon. Acta Physiol. Scand. 67, 313-326.

Braitman, D. J., Auker, C. R. and Carpenter, D. O. (1980). Thyrotropin releasing hormone has multiple actions in cortex. Brain Res. 194, 244-248.

Breese, G. R., Cott, J. M., Cooper, B. R., Prange, A. J. Jr., Lipton, M.A. and Plotnikoff, N.P. (1975). Effects of thyrotropin-releasing hormone (TRH) on the actions of pentobarbital and other centrally acting drugs. J. Pharmacol. Exp. Ther. 193, 11-22.

Bunny, B. S. and Aghajanian, G. K. (1976). Dopamine and norepinephrine innervated cells in the rat prefrontal cortex: pharmacological differentiation using microiontophoretic techniques. Life Sci. 19, 1783-1792.

BURT, D. R. and SNYDER, S.H. (1975). Thyro- tropin releasing hormone ( $\mathrm{TRH}$ ): apparent receptor binding in rat brain membranes. Brain Res. 93, 309-328.

Connor, J.D. (1970). Caudate nucleus neurones: Correlation of the effects of substantia nigra stimulation with iontophoretic dopamine. J. Physiol. 208, 691-703.

Conrad, L.C. A. and Pfaff, D. W. (1976). Autoradiographic tracing of nucleus accumbens efferents in the rat. Brain Res. 113 589-596,

DeFrance, J.F. and Yoshinara, H. (1975). Fimbria input to the nucleus accumbens septi. Brain Res. 90, 159-163.

Dray, A. and OAKLEy, N.R. (1978). Projections from nucleus accumbens to globus pallidus and substantia nigra in the rat. Experientia, 34, 68-70.

Emson, P.C. (1979). Peptides as neurotransmitter candidates in the mammalian CNS. Prog. Neurobiol. 13, 61-116.

Fukuda, N., Nishimura, O., Shikata, M., Hatanaka, C., Mryamoto, M., Saji, Y., Nakayama, R., Fujino, $M$. and NagAwA, Y. (1980). Synthesis and pharmacology of TRH analogs to separate central nervous action from endocrine activity. Chem. Pharm. Bull. 28, 1667-1672.

Fukuda, N., Miyamoto, M., Narumi, S., Nagai, Y., Shima, T. and Nagawa, Y. (1979). Thyrotropin-releasing hormone (TRH): Enhancement of dopamine dependent circling behavior and its own circling-inducing effect in unilateral striatal lesioned animals. Folia Pharmacol. Japon. 75, 251-270.

Goujet, M. A., Simon, P., Chermat, R. and BoisSIER, J.R. (1975). Profile de la T.R.H. en psychopharmacologie expérimentale. Psychopharmacologia (Berlin), 45, 87-92.

Griffiths, E.C., Hooper, K.C., Jeffcoate, S.L. and White, N. (1976). Inactivation of thyrotropin-releasing hormone (TRH) by peptidases in different areas of the rabbit brain. Brain Res. 105, 376-380.

Hökfelt, T., Fuxe, K., Johansson, O., Jeffcoate, S. and White, N. (1975). Distribution of thyrotropin-releasing hormone (TRH) in the central nervous system as revealed with immunohistochemistry. Eur. J. Pharmacol. 34, 389-392.

Ito, N., Ishida, H., Miyakawa, F. and Naito, H. (1974). Microelectrode study of projections from the amygdaloid complex to the nucleus accumbens in the cat. Brain Res. 67, 338-341. Kerwin, R.W. and Русоск, C. J. (1979). Thy- 
rotropin-releasing hormone stimulates release of $\left[{ }^{3} \mathrm{H}\right]$-dopamine from slices of rat nucleus accumbens in vitro. Brit. J. Pharmacol. 67, 323-325.

Kitai, S. T., Sugimori, M. and Kocsis, J. D. (1976). Excitatory nature of dopamine in nigro-caudate pathway. Exp. Brain Res. 24, 351-363.

König, J.F. R. and Klippel, R.A. (1963). The Rat Brain. Williams and Wilkins: Baltimore.

McLennan, H. and York, D. H. (1967). The action of dopamine on neurones of the caudate nucleus. J. Physiol. 189, 393-402.

Miyamoto, M. and Nagawa, Y. (1977). Mesolimbic involvement in the locomotor stimulant action of thyrotropin-releasing hormone (TRH) in the rat. Europ. J. Pharmac. 44, 143-152.

MiYamoto, M., Narumi, S., NAGai, Y., Saji, Y. and NAGAWA, Y. (1979). Thyrotropin-releasing hormone: hyperactivity and mesolimbic dopamine system in rats. Jpn. J. Pharmacol. 29, 335-347.

Miyamoto, M., Fukuda, N., Narumi, S., Nagai, Y., SAJI, Y. and NAGawa, Y. (1981). $\gamma$-butyrolactone- $\gamma$-carbonyl-histidyl-prolinamide citrate (DN-1417): A novel TRH analog with potent effect on central nervous system. Life Sci. 28, 861-869.

Mogenson, G. J., Jones, D. L. and Yim, C. Y. (1980). From motivation to action: functional interface between the limbic system and the motor system. Prog. Neurobiol. 14,69-97.

Morley, J.E. (1979). Extrahypothalamic thyrotropin releasing hormone (TRH)-its distribution and its functions. Life Sci. 25, 15391550.

Narumi, S., Nagai, Y. and Nagawa, Y. (1979). Thyrotropin-releasing hormone (TRH): Action mechanism of an enhanced dopamine release from rat striatal slices. Folia Pharmacol. Japon. 75, 239-250.

Narumi, S. and Nagawa, Y. (1983). Modification of dopaminergic transmission by thyrotropinreleasing hormone. In Segawa, T. Molecular pharmacology of neurotransmitter receptors. pp. 185-197, N. Y.: Raven Press.

Nauta, W. J. M., Smith, G. P., Faull, R. L. M. and Demesick, V.B. (1978). Efferent connections and nigral afferent of the nucleus accumbens septi in the rat. Neuroscience, $\mathbf{z}$, 385-401.

Oomura, Y., Ooyama, H., Sugimori, M., Yoneda, K. and Simpson, A. (1976). Constant current device for drug application studies in the central nervous system. Physiol. Behav. 16, 799-802.

Plotnikoff, N.P., Prange, A. J. Jr., Breese, G. R., Anderson, M.S. and Wilson, I.C. (1972). Thyrotropin releasing hormone: enhancement of dopa activity by a hypothalamic hormone. Science, 178, 417-418.

Renaud, L.P. and Martin, J.B. (1975). Thyrotropin releasing hormone $(\mathrm{TRH})$ : depressant action on central neuronal activity. Brain Res. 86, 150-154.

Shikata, M., Tsuda, M., Saji, Y. and NaGawa, Y. (1982). Relationship between receptorbinding affinities and TSH-releasing activities of novel TRH analogs in the rat. Jpn. J. Pharmacol. 32, 883-891.

SNyder, S. H. (1980). Brain peptides as neurotransmitters. Science, 209, 976-983.

Spencer, H. J. and Havlicek, V. (1974). Alterations by anesthetic agents of the responses of rat striatal neurons to iontophoretically applied amphetamine, acetylcholine, noradrenaline and dopamine. Canad. J. Physiol. Pharmacol. 52, 808-813.

Stone, T. W. and Bailey, E. V. (1975). Responses of central neurones to amantadine: comparison with dopamine and amphetamine. Brain Res. 85, 126-129.

Takaori, S., Sasa, M., Akaike, A. and Fujimoto, S. (1981). Dopamine and neuron activity in the meso-telencephalic system-an electrophysiological study. Advance in the Biosciences, 37, 341-355.

Winokur, A. and Utiger, R. D. (1974). Thyrotropin-releasing hormone: regional distribution in rat brain. Science, 185, 265-267.

Winokur, A. and Beckman, A.L. (1978). Effects of thyrotropin releasing hormone, norepinephrine and acetylcholine on the activity of neurons in the hypothalamus, septum and cerebral cortex of the rat. Brain Res. 150, 205-209.

Woodruff, G. N., MaCarthy, P.S. and Walker, R. J. (1976). Studies on the pharmacology of neurones in the nucleus accumbens of the rat. Brain Res. 115, 233-242.

YARBRough, G.G. (1976). TRH potentiates excitatory actions of acetylcholine on cerebral cortical neurones. Nature, 263, 523-524.

Yim, C. Y. and Mogenson, G. J. (1982). Responses of nucleus accumbens neurons to amygdala stimulation and its modification by dopamine. Brain Res. 239, 401-415. 